\title{
下水污泥のバイオソリッド燃料化および燃焼特性*
}

\author{
安田 俊彦*1, 金田 聡*2, 中村 紀之 ${ }^{* 2}$, 北野 徳之 ${ }^{* 2}$
}

\section{Production of Biosolid Fuel from Sewage Sludge and Combustion Characteristics}

\author{
Toshihiko YASUDA ${ }^{*}$, Satoshi KANEDA, Noriyuki NAKAMURA and Noriyuki KITANO \\ ${ }^{* 1}$ HITACHI ZOSEN CORPORATION, 2-11, Funamachi 2-chome, Taisyo-ku, Osaka, 551-0022 Japan
}

We have developed the sewage sludge drying and pelletizing process that transforms sewage into low water content (less than 10\%) and spherical pellet. This report introduces the description of the sewage sludge drying and pelletizing process, quality of dried sludge pellets, the basic results of the co-firing test of dried sludge pellets with coal in pulverized coal-fired furnace and municipal solid waste incinerator. It is concluded that dried sludge pellets had low water content and about $1 / 2 \sim 2 / 3$ of heat value of coal. Also, co-firing of dried pellet results in good operation in pulverized coal-fired furnace and municipal solid waste incinerator.

Key Words : Sewage, Biosolid, Fuel, Dryer, Pelletize

\section{1. 緒言}

近年，地球温暖化ガス排出量の削減対策として各種バイオマスの燃料利用が注目されている，バイオマスを燃 料として利用した場合, カーボンニュートラルとみなし二酸化炭素の増減に影響を与えないとされている. バイ オマスの一つである下水污泥は全国の下水処理場から毎日大量に排出されており, セメント原料, 建設資材, 堆 肥等に再利用されているが，一部は埋立処分されている. 下水污泥燃料化装置は, 脱水機等で含水率 $80 \%$ 程度ま で脱水された下水污泥 (脱水污泥)を原料とし, 脱水污泥が有寸る熱量を損なうことなく含水率 $10 \%$ 以下かつ直径 数ミリ程度の粒状に乾燥造粒できる性能を有寸る. 本装置にて製造したバイオソリッド然料の一例を図 1 に示す. また，下水処理場における本装置の概念図を図 2 に示す，バイオソリッド然料の利用先は，主に石炭火力発電所 等の微粉炭ボイラを対象としていたが，都市ごみ焼却炉における代替燃料利用について検討を行った.

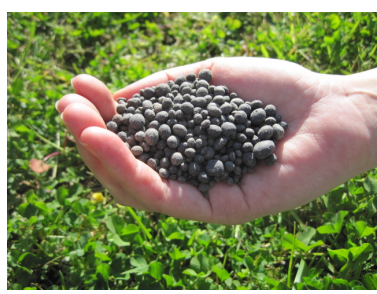

Fig.1 Biosolid fuel from sewage sludge

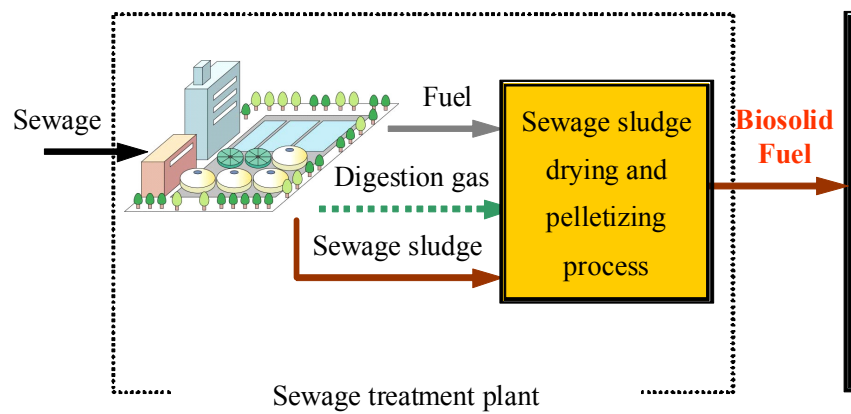

(1)Coal-fired power plants (2) Chemical plants (3) Cement plants (4) Municipal solid waste incinerator

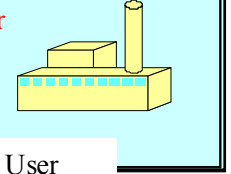

Fig.2 Conceptual diagram of production of biosolid fuel

\footnotetext{
原稿受付 2011 年 8 月 29 日

*1 正員, 日立造船 (株) 事業·製品開発本部（广551-0022 大阪府大阪市大正区船町 2-2-11）

*2 日立造船 (株) エンジニアリング本部

E-mail: yasuda_to@hitachizosen.co.jp
} 


\section{2. 装置の概要}

本装置は熱媒体として熱媒油を使用した間接加熱型の乾燥方式であり，含水率 $80 \%$ 程度の脱水污泥を含水率 $10 \%$ 以下まで乾燥する機能と, 直径数ミリ程度の粒状に造粒する機能を併せ持つ装置である. 本装置の概略フロ 一は図 3 に示すとおり, 主に 3 つの機器で構成される.

(1)熱媒加熱装置 : 熱媒体である熱媒油を加熱するとともに, 乾燥造粒装置の排ガスを取込み, 燃焼脱臭を兼用 する.

(2)乾燥造粒装置 : 間接加熱方式により脱水污泥の乾燥および造粒を同時に行う.

(3)スクラバ : 乾燥造粒装置排ガスの冷却除湿を行う.

なお，熱媒油加熱器に必要な燃料分を入力したエネルギーとした場合，原料の脱水污泥の発熱量にもよるが， 約 1.3 倍 ${ }^{(1)}$ のエネルギーを持つバイオソリッド然料を得ることができる.

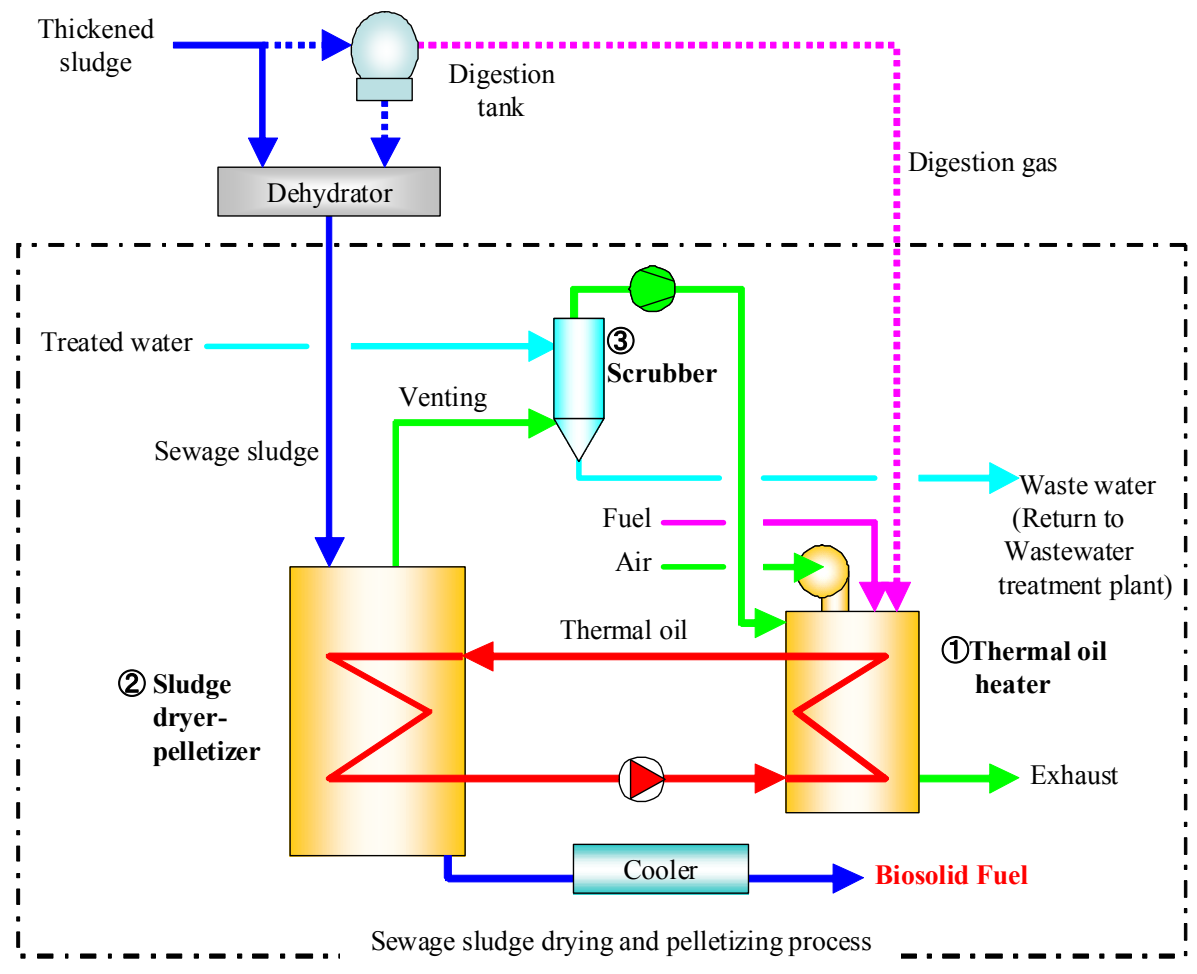

Fig.3 Process Flow

\section{3. バイオソリッド燃料の特長}

\section{$3 \cdot 1$ 発熱量}

脱水污泥から製造したバイオソリッド燃料の低位発熱量の分析例を表 1 に示す．バイオソリッド燃料は，脱水 污泥中の有機分を損なうことなく乾燥造粒することで，石炭の低位発熱量の約半分〜 $2 / 3$ に相当する高い発熱量 を有する.

Table 1 Characteristics of Biosolid fuel

\begin{tabular}{|c|c||c|c|c|}
\hline Item & Unit & Biosolid fuel A & Biosolid fuel B & Coal (for ref.) \\
\hline \hline Moisture & $\%$ & 4.0 & 4.8 & 2.6 \\
\hline Ash & $\%$ & 25.1 & 13.9 & 13.8 \\
\hline Volatile matter & $\%$ & 60.5 & 74.8 & 28.2 \\
\hline Fixed carbon & $\%$ & 10.4 & 6.5 & 55.4 \\
\hline High calorific value & $\mathrm{MJ} / \mathrm{kg}$ (Dry base) & 17.1 & 19.8 & 28.7 \\
\hline Low calorific value & $\mathrm{MJ} / \mathrm{kg}$ (Dry base) & 15.8 & 18.3 & 27.7 \\
\hline
\end{tabular}




\section{$3 \cdot 2$ 安全性}

バイオソリッド燃料貯留時の安全性を検証するために，自然発火性および吸湿性の試験を実施した。自然火発火 性試験では初期温度 $140^{\circ} \mathrm{C}, 150^{\circ} \mathrm{C}$ とも 24 時間経過後も温度上昇はみられなかった. 乾燥造粒装置で約 $120^{\circ} \mathrm{Cまで}$ 加熱されたバイオソリッド然料は, 冷却機で $40^{\circ} \mathrm{C}$ ま゙急速冷却されるため, 貯留時に発火する危険性は低い. ま た, 吸湿性試験では初期含水率が約 $4 \%$ のバイオソリッド然料を温度 $28^{\circ} \mathrm{C}$, 湿度 $90 \%$ の恒温状態で 90 日間保管 した結果，一般的に発酵する可能性は低いことが知られている含水率 $20 \%$ 以下の低水分 ${ }^{(2)}$ を十分に保持できた.

\section{4. 石炭との混焼試験}

\section{$4 \cdot 1$ 試験概要}

石炭火力発電所等での微粉炭ボイラにおけるバイオソリッド燃料の利用を想定し，バイオソリッド燃料と石炭 の混焼試験を財団法人電力中央研究所エネルギー技術研究所の石炭燃焼試験炉（燃料投入量 : 約 $100 \mathrm{~kg} / \mathrm{h}$ ) にて 実施した．使用した燃焼試験装置は長さ $8 \mathrm{~m} ，$ 内径 $1 \mathrm{~m}$ の鋼板製横置円筒型水冷炉で，低 N0x 燃焼が行えるよう， 流れ方向に二段燃焼用空気（二次空気）注入ポートが設置されている. 燃焼試験は石炭に対し 5\%（発熱量ベー ス）の割合でバイオソリッド燃料を混合した混合燃料と石炭単独の 2 ケースにて実施した。また，試験に使用し たバイオソリッド燃料と石炭（豪州産）の分析結果および混合燃料の計算值を表 2 に示す.

Table 2 Results of Analysis

\begin{tabular}{|c|c||c|c|c|}
\hline Item & Unit & Biosolid fuel & Coal & (Biosolid+Coal) \\
\hline \hline Moisture & $\%$ & 2.1 & 2.6 & 2.6 \\
\hline Ash & $\%$ & 33.6 & 13.8 & 15.7 \\
\hline Volatile matter & $\%$ & 58.9 & 28.2 & 31.2 \\
\hline Fixed carbon & $\%$ & 5.4 & 55.4 & 50.5 \\
\hline Carbon & $\%($ dry base) & 35.0 & 73.7 & 69.96 \\
\hline Hydrogen & $\%($ dry base) & 5.0 & 4.51 & 4.56 \\
\hline Nitrogen & $\%($ dry base) & 6.01 & 1.58 & 2.00 \\
\hline Oxygen & $\%($ dry base) & 18.4 & 5.8 & 7.02 \\
\hline
\end{tabular}

\section{$4 \cdot 2$ 試験結果}

\section{$4 \cdot 2 \cdot 1$ 火炉内の温度分布}

図 4 に火炉中心軸上における温度分布（二次空気注入位置 : バーナ端から 2.99m）を示す. バーナ近傍では, 石炭にバイソリッド然料を混合し燃焼した混焼時の温度が，石炭のみを燃焼した石炭専焼時に比べて低下する. これは，バイオソリッド燃料の発熱量が石炭の半分程度なので，混焼時の方が石炭専焼時よりも燃料投入量が多 くなるが，A/C (一次空気量/燃料流量）は一定なので, 混焼時のバーナ吹き出し流速が速くなり, 酸素濃度の 低下により温度が低下するものと考えられる。しかし，混焼時および石炭専焼時のいずれの場合も，最高温度が $1,400^{\circ} \mathrm{C}$ 達し, 変化傾向もほぼ同じことから, 混焼によって温度分布に大きな影響は与えないことがわかる.よ ってボイラ効率への影響もほとんど無いと予測される.

\section{$4 \cdot 2 \cdot 2$ 排ガス性状}

バイオソリッド然料は石炭と比較して窒素含有率が高いため, バイオソリッド燃料が NOx 濃度に与える影響を 検討した. 図 5 に, 二次空気比 (二次空気量／総空気量）を変化させたときの炉出口における NOx 濃度の測定結 果を示寸. 二段燃焼率が 10\%以上においては，混焼時の方が専焼時に比べて NOx が低下する. バイオソリッド燃 料の揮発分が石炭に比べて多く, 揮発分中の NOx 還元物質（アンモニア等）の放出量が多いことが考えられる. また，前述の図 4 より火炉内の温度分布において混合燃料の方が若干低い傾向にあり，サーマル NOx が低くなっ たことが考えられる. SOx 濃度は測定していないため, 燃料中の燃焼性硫黄が全量 $\mathrm{SO}_{2}$ に転換したものと仮定する と，石炭専焼時で $185 \mathrm{ppm} ，$ 混焼時で $271 \mathrm{ppm}$ と試算される. 


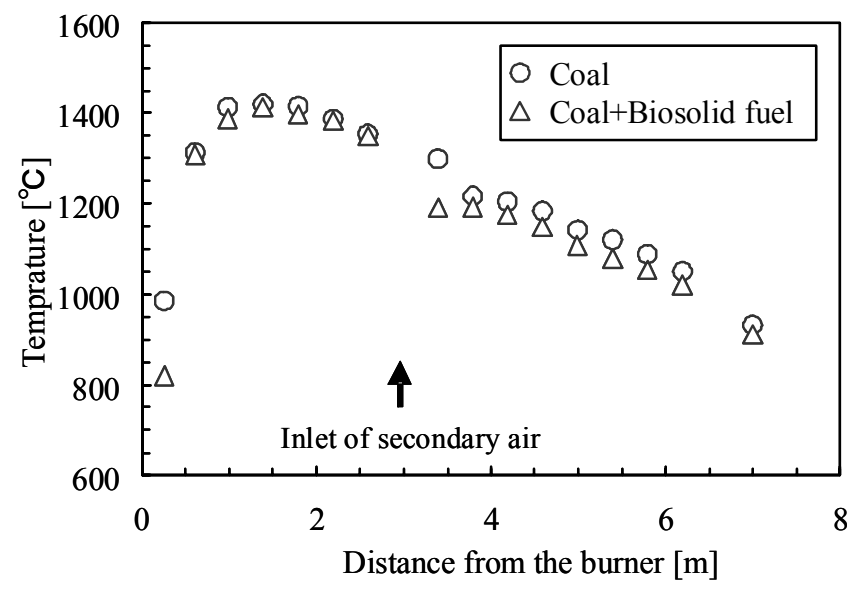

Fig.4 Temperature at the distance from the burner.

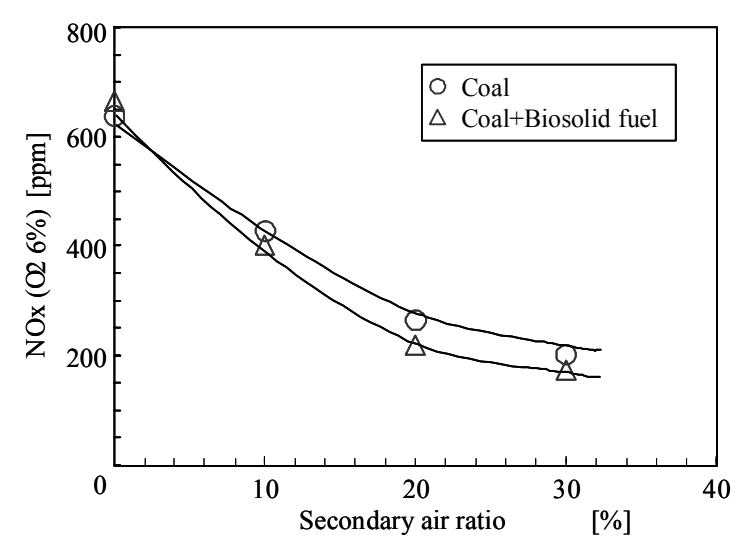

Fig.5 Relationship between secondary air ratio and NOx concentration

\section{5. 都市ごみ焼却炉における混焼試験}

\section{$5 \cdot 1$ 試験概要}

都市ごみ焼却炉において, 都市ごみに比べ高発熱量のバイオソリッド燃料を代替燃料として混焼することで次 のような利点がある.

・地産地消

・全国的に利用可能な施設が増える.

・ボイラ発電付の場合, 発電量が増える.

・ごみの熱量が低い焼却炉の補助燃料を低減できる.

・地球温暖化ガス排出量の削減に寄与する.

試験を実施した都市ごみ焼却炉は処理能力 $135 \mathrm{t} /$ 日（一炉当り）のガス化溶融炉で，バイオソリッド燃料は， 都市ごみ投入量に対し 5.6〜6.7\%の割合で定量的に投入した.

\section{$5 \cdot 2$ 試験結果}

\section{$5 \cdot 2 \cdot 1$ 蒸気流量と発電電力量}

図 6 に混焼試験前後の蒸気流量と発電電力量の測定値および平均值を示す，混焼試験開始後, 蒸気量は $3.7 \sim$ $9.3 \%(0.7 \sim 1.7 \mathrm{t} / \mathrm{h})$, 発電電力量も $3.8 \sim 8.8 \%(0.21 \sim 0.48 \mathrm{MW})$ 増加した. 混焼試験前後の入熱量を運転デー タより試算すると，混焼前で $8.5 \mathrm{MJ} / \mathrm{kg}$ (湿ベース)，混焼中は $9.3 \sim 10 \mathrm{MJ} / \mathrm{kg}$ となり，0.8〜 $1.5 \mathrm{MJ} / \mathrm{kg}$ の増加とな る. バイオソリッド燃料の低位発熱量（15.7MJ/kg）より入熱量を試算した場合， $0.8 \sim 1.1 \mathrm{MJ} / \mathrm{kg}$ （投入割合 : 5.6 〜 6.7\%) の増加となり, これはほぼ運転データと一致することから, 蒸気流量と発電電力量の増加はバイオソリ ッド然料によるものと予測される.

\section{$5 \cdot 2 \cdot 2$ 排ガス性状}

表 3 に混焼試験前後の NOx およびSOx 濃度の測定值を示す. NOx 濃度にほとんど変動はみられないが, SOx 濃度 は約 $10 \mathrm{ppm} の$ 上昇がみられた。 バイオソリッド然料中の硫黄が全量 SOx に転換した場合, 約 $60 \mathrm{ppm} の$ 上昇になる が, 一部が硫化物や硫酸化合物として飛灰に移行しているものと予測される. 


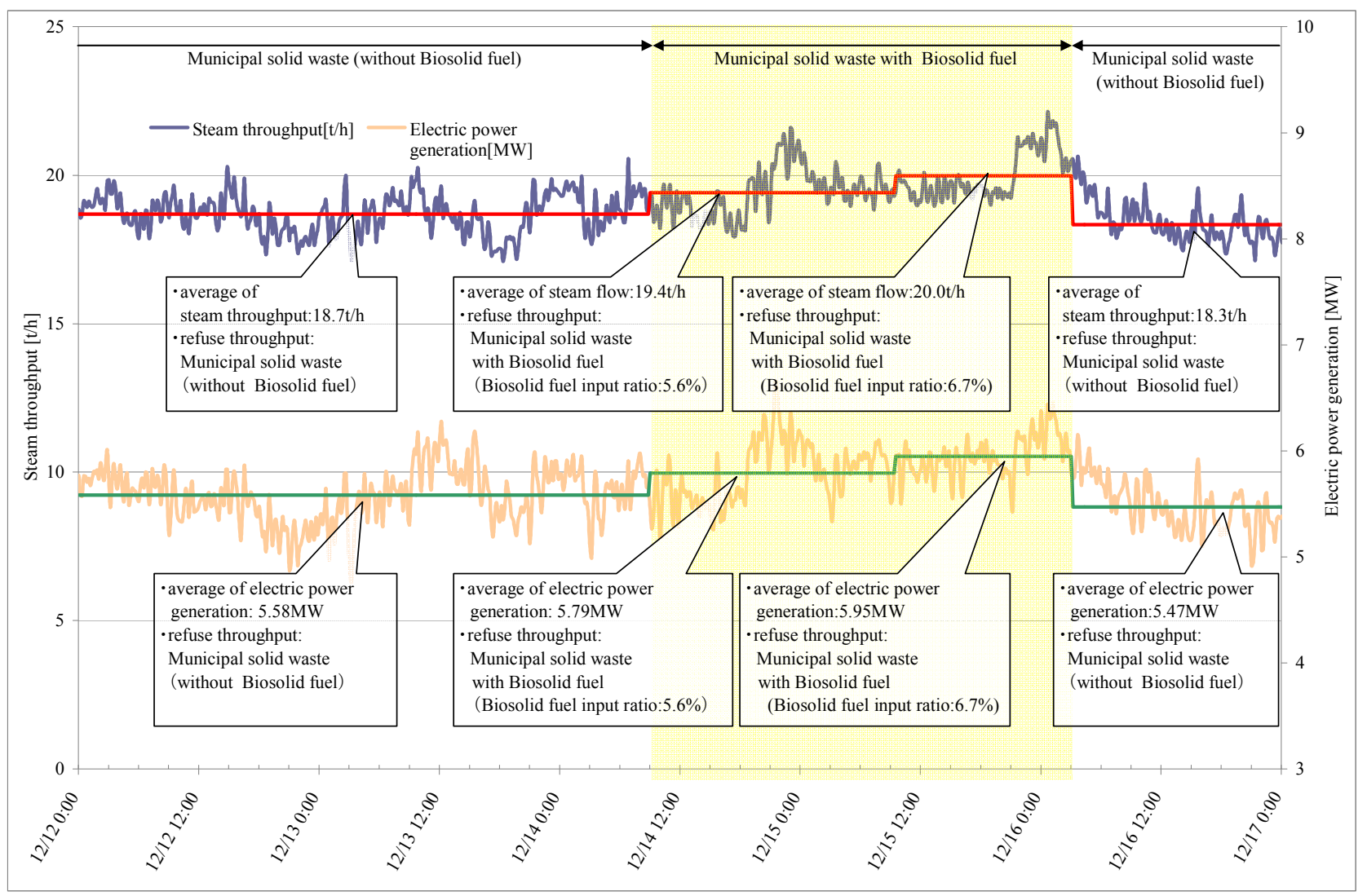

Fig.6 Transition of steam throughput and electric power generation

Table 3 Characteristics of Flue gas with/without Biosolid fuel

\begin{tabular}{|l|l||c|c|}
\hline \multicolumn{2}{|c|}{ Item } & $\begin{array}{c}\text { Municipal solid waste } \\
\text { (without Biosolid fuel) }\end{array}$ & $\begin{array}{c}\text { Municipal solid waste } \\
\text { with Biosolid fuel }\end{array}$ \\
\hline \hline \multirow{2}{*}{$\begin{array}{l}\text { SOx } \\
(\mathrm{ppm})\end{array}$} & measured value & 4.5 & 14.1 \\
\cline { 2 - 4 } & corrected at $12 \% \mathrm{O}_{2}$ & 2.4 & 8.6 \\
\hline \multirow{2}{*}{$\begin{array}{l}\mathrm{NOx} \\
(\mathrm{ppm})\end{array}$} & measured value & 207 & 225 \\
\cline { 2 - 4 } & corrected at $12 \% \mathrm{O}_{2}$ & 137 & 138 \\
\hline \multicolumn{2}{|l|}{ ratio of $\mathrm{O}_{2}(\%)$} & 7.4 & 6.3 \\
\hline
\end{tabular}

\section{6. 結 言}

下水污泥然料化装置は，下水污泥を乾燥および造粒することで，高い発熱量を有する取扱性の優れた「バイオ ソリッド然料」を製造することができる．製造したバイオソリッド然料は，石炭と混焼することで石炭の使用量 を削減し，地球温暖化ガス排出量の削減に寄与することができる，バイオソリッド燃料の然焼性について，石炭 との混焼および都市ごみ焼却炉における混焼実験を実施し良好な結果が得られた。都市ごみ焼却炉を新たなバイ オソリッド然料の利用先にできれば，ほぼ全国各地にて利用先を確保でき，地産地消を確立することが可能とな る.

\section{文献}

(1) 日立造船株式会社（技術提案者）, LOTUS Project スラッジ・ゼロ・ディスチャージ技術 下水污泥のバイオソリ ッド燃料化に係る技術評価書，下水道技術開発プロジェクト (SPIRIT21) 委員会, p. 87.

(2) 藤田賢二，コンポスト技術一廃棄物有効利用のテクノロジーー，技報堂出版，p. 66 . 